\title{
Atmospheric Motion Vectors from Model Simulations. Part I: Methods and Characterization as Single-Level Estimates of Wind
}

\author{
NiEls Bormann and Angeles HernandeZ-CARRASCAL \\ European Centre for Medium-Range Weather Forecasts, Reading, United Kingdom \\ RÉGIS BORDE AND HANS-JOACHIM LUTZ \\ European Organisation for the Exploitation of Meteorological Satellites (EUMETSAT), Darmstadt, Germany \\ JASON A. OTKIN AND STEVE WANZONG \\ Cooperative Institute for Meteorological Satellite Studies, University of Wisconsin-Madison, Madison, Wisconsin
}

(Manuscript received 7 December 2012, in final form 23 August 2013)

\begin{abstract}
The objective of this study is to improve the characterization of satellite-derived atmospheric motion vectors (AMVs) and their errors to guide developments in the use of AMVs in numerical weather prediction. AMVs tend to exhibit considerable systematic and random errors that arise in the derivation or the interpretation of AMVs as single-level point observations of wind. One difficulty in the study of AMV errors is the scarcity of collocated observations of clouds and wind. This study uses instead a simulation framework: geostationary imagery for Meteosat- 8 is generated from a high-resolution simulation with the Weather Research and Forecasting regional model, and AMVs are derived from sequences of these images. The forecast model provides the "truth" with a sophisticated description of the atmosphere. The study considers infrared and water vapor AMVs from cloudy scenes. This is the first part of a two-part paper, and it introduces the framework and provides a first evaluation in terms of the brightness temperatures of the simulated images and the derived AMVs. The simulated AMVs show a considerable global bias in the height assignment $(60$ $75 \mathrm{hPa}$ ) that is not observed in real AMVs. After removal of this bias, however, the statistics comparing the simulated AMVs with the true model wind show characteristics that are similar to statistics comparing real AMVs with short-range forecasts (speed bias and root-mean-square vector difference typically agree to within $1 \mathrm{~m} \mathrm{~s}^{-1}$ ). This result suggests that the error in the simulated AMVs is comparable to or larger than that in real AMVs. There is evidence for significant spatial, temporal, and vertical error correlations, with the scales for the spatial error correlations being consistent with estimates for real data.
\end{abstract}

\section{Introduction}

Atmospheric motion vectors (AMVs) derived from images from geostationary or polar satellites have long been an established ingredient in global and regional assimilation systems for numerical weather prediction (NWP). At this time, AMVs largely provide the only source of upper-level wind observations over the oceanic areas. The winds are derived by tracking targets such as clouds or water-vapor structures across image sequences (e.g., Nieman et al. 1997; Velden et al. 1997;

Corresponding author address: Niels Bormann, ECMWF, Shinfield Park, Reading RG2 9AX, United Kingdom.

E-mail: n.bormann@ecmwf.int
Schmetz et al. 1993; Holmlund 2000). An estimate of the appropriate height or pressure level is also provided by the wind producers, and this estimate is mostly based on an estimate of the cloud top (for high-level winds) or the cloud base (for low-level winds).

A good characterization of errors and biases is essential for the near-optimal assimilation of any observation. AMVs tend to exhibit considerable systematic errors and geographically varying quality, as shown in comparisons with radiosonde or model data (e.g., Bormann et al. 2002; Cotton and Forsythe 2012). In recent years, further progress on the improved use of AMVs in assimilation systems has been hampered, for instance, by limited knowledge of the detailed error characteristics (systematic and random) and the origin of these errors. 
Errors can arise in the wind derivation, for instance, from the recognized difficulties of assigning an appropriate height, from incorrect tracking, and so on, but they can also arise from the use of nonpassive tracers in the tracking step or the interpretation of AMVs as single-level point observations of wind (e.g., Velden and Bedka 2009). Study of these aspects with real data is often difficult because of a lack of detailed collocated observations of both wind and clouds.

In the current study we use a simulation framework in which AMVs are derived from synthetic satellite images that are computed from an NWP model simulation. Here, the model simulation serves as truth and provides complete knowledge of the atmospheric structure that led to the derived AMV field, including the detailed distribution of clouds. Similar approaches have been used in the past-for instance, to understand characteristics of clear-sky water vapor winds (Kelly et al. 1998), to investigate some aspects of cloudy AMVs (von Bremen 2008), or to test new AMV algorithms for future satellite instruments (Wanzong et al. 2008). Our study builds on exploratory work of von Bremen (2008), who investigated AMVs derived from sequences of Meteorological Satellite-8 (Meteosat-8) images simulated from a $10-\mathrm{km}$-resolution forecast from the European Centre for Medium-Range Weather Forecasts (ECMWF) global model over a 6 -h period. The comparison of the derived AMVs with the model truth showed that the simulated AMVs exhibited a number of characteristics that are commonly found in monitoring statistics of real AMVs against short-range forecasts, thus showing the feasibility of using a simulation framework to characterize AMVs. The study that is presented here uses a higher-resolution simulation obtained with a regional model over a 24-h period, thereby significantly improving on the spatial resolution and the length of the study period.

This paper is the first part of a two-part series of papers, and it introduces the simulation framework, assesses the realism of the image simulations, and provides a first analysis of the derived AMVs. The structure is as follows: section 2 describes the main characteristics of the model used in the simulation, the method used to simulate the images, and the derivation system used to produce AMVs from the simulated imagery. In section 3, cloud structures from observed and simulated images are compared to assess the realism of the simulated imagery. Section 4 presents a statistical evaluation of AMVs, interpreted as single-level point estimates of wind, by comparing them with the model truth. This analysis is followed by an analysis of the horizontal, vertical, and temporal correlations of errors. Conclusions are presented in the last section. The second paper (Hernandez-Carrascal and Bormann 2014, hereinafter

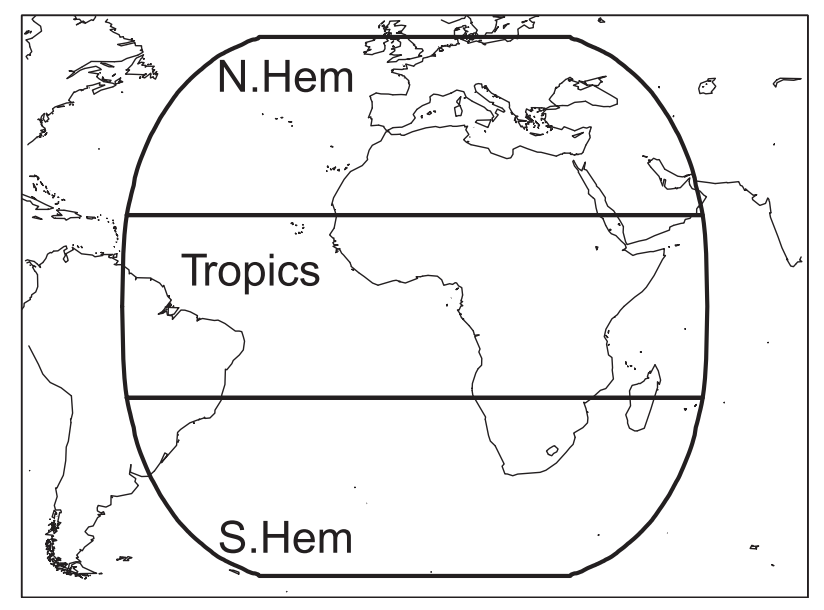

FIG. 1. Domain of the WRF simulation, together with the coverage of the Meteosat- 8 disk considered in this study. Also shown are the geographical areas for which statistics for the AMVs will be presented later.

Part II) focuses on observation-operator aspects, that is, on the interpretation of AMVs.

\section{Model data, simulated images, and AMV derivation}

\section{a. WRF simulation}

This study uses a simulation performed with the Weather Research and Forecasting (WRF) model, a compressible nonhydrostatic regional NWP model described in Skamarock et al. (2005). The simulation covers the 24-h period starting at 0000 UTC 16 August 2006 and is described in Otkin et al. (2009), who used it to generate half-hourly synthetic geostationary imagery to study WRF cloud fields and to prepare for future geostationary satellite instruments. The dataset was produced with version 2.2 , run over a domain covering the prime Meteosat disk (within $\pm 58.8^{\circ}$ latitude; see Fig. 1), with a resolution that varies from $3 \mathrm{~km}$ at the equator to $1.7 \mathrm{~km}$ at the northern and southern boundaries. The simulation employed 52 levels in the vertical direction, with a model top located at $28 \mathrm{hPa}$. The WRF model was initialized at 1800 UTC 15 August 2006 from $1^{\circ}$ analyses taken from the Global Data Assimilation System (GDAS). At the time, the operational GDAS was run at a resolution of T382 $(\approx 35 \mathrm{~km})$, employing 6-hourly threedimensional variational data assimilation of a wide range of conventional and satellite data. The study period is covered through a 6-30-h WRF forecast; that is, the spinup period allowed to develop finescale structures from the coarser-resolution initialization analysis is $6 \mathrm{~h}$. Full model output every $15 \mathrm{~min}$ was available during the study period. 
The WRF model includes various microphysical quantities as prognostic variables. These are parameterized using the Thompson et al. (2008) mixed-phase cloud microphysics scheme. The simulation also employed the Mellor-Yamada-Janjić planetary boundary layer scheme (Mellor and Yamada 1982). No cumulus parameterization was used, and any clouds were explicitly predicted by the microphysics scheme. Given the grid resolution, this means some small-scale convection is absent from our simulations.

Given the size of the domain and the high spatial resolution, the generation of the WRF dataset required significant computational resources, including 1.5 TByte of physical memory and 87000 CPU hours on the "cobalt" supercomputer at the University of Illinois.

\section{b. Radiative transfer simulation}

The Spinning Enhanced Visible and Infrared Imager (SEVIRI) images for the WRF dataset were simulated every 15 min over the study period using version 9 of the Radiative Transfer for the Television and Infrared Observation Satellite Operational Vertical Sounder package (RTTOV; Saunders et al. 2008), following Chevallier and Kelly (2002). All infrared channels of SEVIRI were simulated over the prime Meteosat disk (except for areas north of $58.8^{\circ} \mathrm{N}$ and south of $58.8^{\circ} \mathrm{S}$ because of the limited-area domain of the model simulation). Ocean surface emissivities were modeled using the Infrared Surface Emissivity Model (ISEM; Sherlock 1999), whereas the land surface emissivity was set to 0.99 over moist areas and 0.93 over dry land, with no variation by channel. The WRF simulation was complemented with data from a global simulation with the ECMWF system above the WRF model top ( $28 \mathrm{hPa}$ ). To mimic the SEVIRI viewing geometry, for each SEVIRI pixel, brightness temperatures (BTs) were calculated from a weighted spatial average of the relevant full-resolution atmospheric model profiles and surface parameters. Instrument noise has not been simulated for the images, because our aim is to characterize the errors arising in the processing and the interpretation of AMVs.

Cloud contributions in RTTOV are modeled through a multistream scattering parameterization as described in Matricardi (2005). The parameterization uses layer values of cloud fraction, cloud liquid water, and cloud ice. The ice water content is converted into a distribution of the effective diameters of ice particles using the model of McFarquhar et al. (2003), and the assumed shape of the ice crystals is aggregates. The WRF simulation output provides detailed information on microphysical species, but for the purpose of using RTTOV these were combined into one liquid cloud category and one ice cloud category, the latter being a combination of all ice hydrometeors available from WRF (i.e., pristine ice, snow, and graupel). These choices were found to give the most realistic image simulations. Cloud fraction was calculated from the spatial weighting of atmospheric profiles, assuming a cloud fraction of 1 for each contributing model grid point at which some cloud is present.

\section{c. AMV derivation}

AMVs were derived by the European Organisation for the Exploitation of Meteorological Satellites (EUMETSAT) from the simulated imagery by tracking cloudy targets in SEVIRI's $6.2-\mu \mathrm{m}$ water vapor (WV) channel and the $10.8-\mu \mathrm{m}$ infrared (IR) channel. Clearsky winds or WV winds derived from the $7.3-\mu \mathrm{m}$ channel are not considered here.

The AMV derivation uses a prototype derivation system developed in preparation for Meteosat Third Generation imagery (Borde et al. 2011), with some differences with respect to the one used by EUMETSAT operations at the time (Schmetz et al. 1993; Holmlund 2000). The starting point is a triplet of consecutive images, with an interval of $15 \mathrm{~min}$ between them. Cross correlation is used for the tracking step, and the cross-correlation contribution (CCC) method is used to determine the pixels of the feature tracked and subsequently to assign both height and horizontal location to each motion vector (Borde and Oyama 2008). An estimate of the cloud-top pressure for individual pixels within each tracked feature is obtained from the cloud analysis (CLA) product. This step makes use of atmospheric background information of temperature and humidity, usually obtained from a short-range forecast. In our case, the model truth was used in this step, with the WRF simulation subsampled 3 hourly and to $0.25^{\circ}$ spatial resolution, as required by the EUMETSAT processing algorithm. Note that this choice of background data eliminates errors arising from forecast errors in the background data. An automatic model-independent quality index (QI) is calculated for each AMV, following Holmlund (1998).

\section{Evaluation of image characteristics}

As a first step, we will now analyze the characteristics of the simulated images in comparison with observed imagery. This is important to establish the realism of the imagery, particularly in terms of the general distribution of clouds and the effective resolution of the imagery, as both will be affecting the AMV derivation. For the purpose of this study, the quality of the forecast in the traditional sense is relatively unimportant. It is not necessary that the forecasts agree well with the observed images for a given time and place; in particular, misplacements of weather systems in the forecasts are of no 

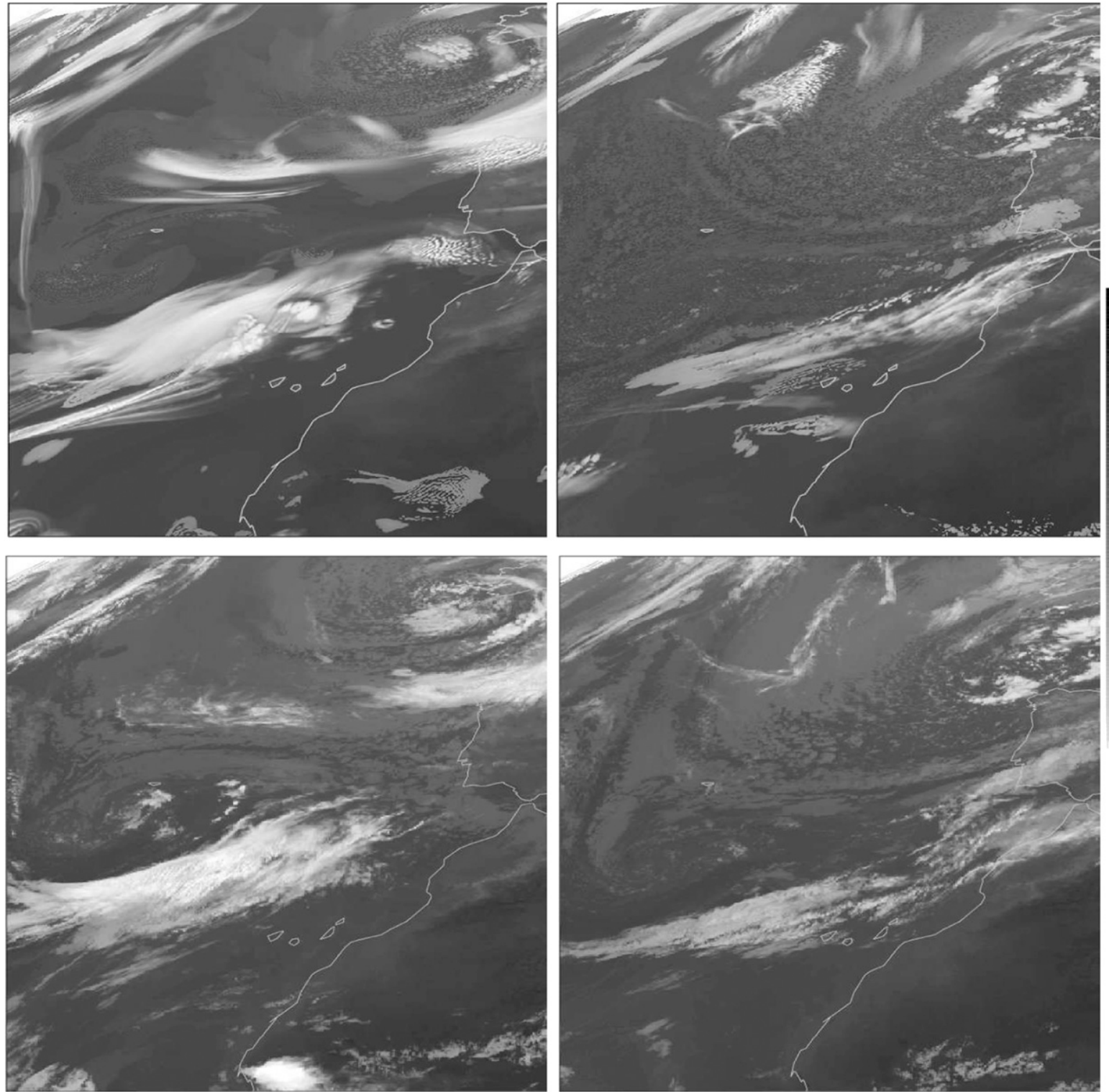

FIG. 2. (top) WRF-simulated images and (bottom) observed satellite images (K) in the 10.8- $\mu \mathrm{m}$ band of SEVIRI, zoomed over the eastern North Atlantic Ocean for (left) 0000 UTC 16 Aug and (right) 0000 UTC 17 Aug 2006 (i.e., respectively the beginning and the end of the study period).

relevance. What is important is that the general appearance, effective spatial resolution, and variability of cloud structures in the simulated imagery agree well with the observed imagery.

\section{a. Visual comparison of images}

A visual comparison of simulated and observed images (see Fig. 2) provides a useful first impression about cloud structures and some qualitative characteristics of the two sets of images. At the end of the study period (right columns), the simulated images show a generally realistic level of spatial detail and cloud distributions.
Although some cloud systems are represented differently or misplaced in the simulations when compared with the observations, they nevertheless appear reasonable, even though the marine stratocumulus areas seem somewhat too noisy (see the area of darker gray shading to the west of Spain). At the beginning of the study period the extent of cirrus clouds appears to be overestimated and some clouds lack spatial variability. A likely reason for these features is that the WRF simulation seems to be still developing finescale structures during the early hours of our study period; that is, the 6-h spinup allowed before our study period appears not to 

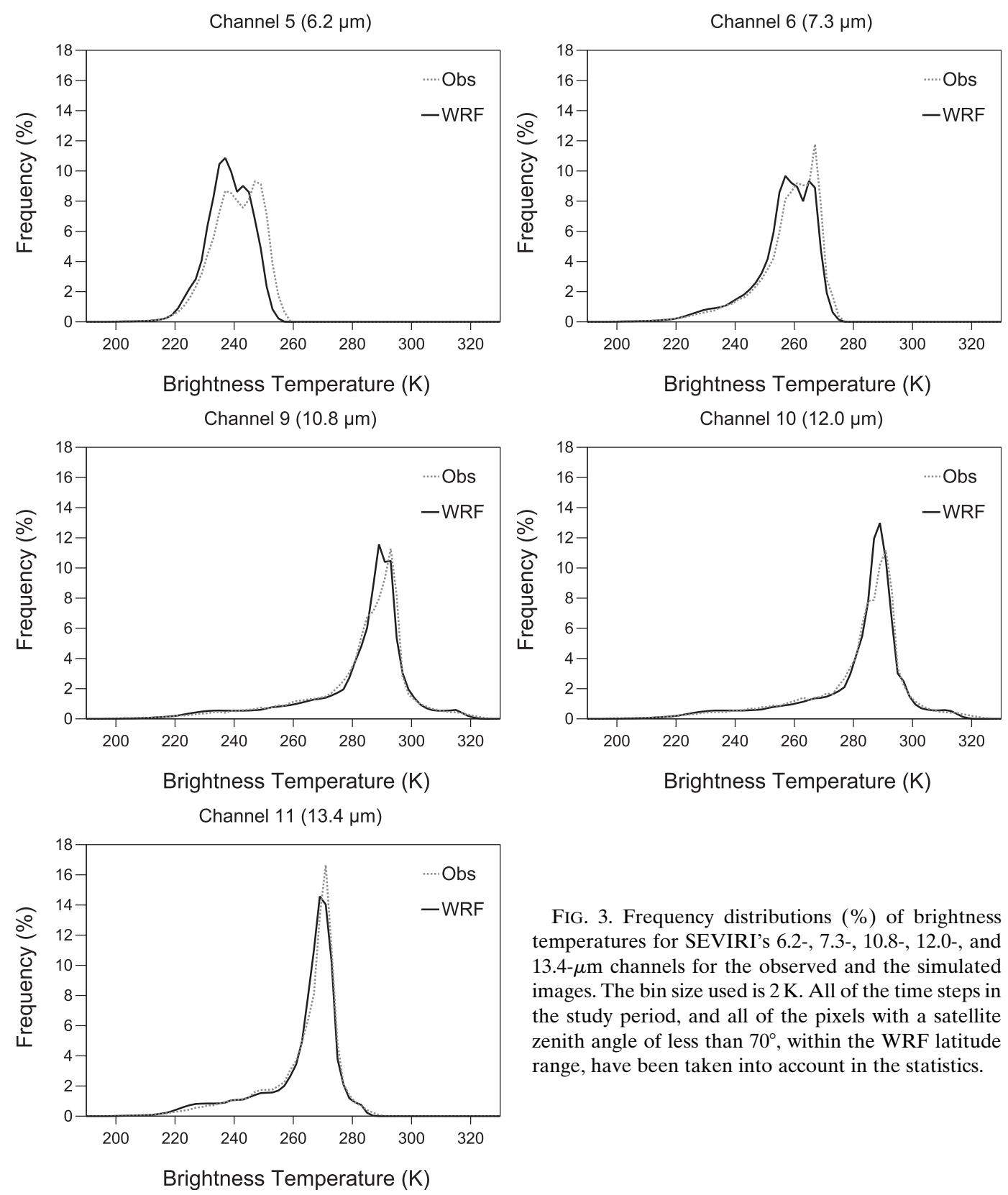

FIG. 3. Frequency distributions (\%) of brightness temperatures for SEVIRI's 6.2-, 7.3-, 10.8-, 12.0-, and 13.4- $\mu \mathrm{m}$ channels for the observed and the simulated images. The bin size used is $2 \mathrm{~K}$. All of the time steps in the study period, and all of the pixels with a satellite zenith angle of less than $70^{\circ}$, within the WRF latitude range, have been taken into account in the statistics.

be sufficient. Similar findings were reported by Otkin et al. (2009) in their investigation of imagery derived from this simulation. This situation affects the first 9-12 h of the study period, as further quantified below.

\section{b. Frequency distributions of brightness temperatures}

The frequency distributions of BTs suggest a comparable distribution of cloud structures in the vertical direction for the simulations and the observed imagery (Figs. 3 and 4). The longwave infrared channels $(10.8-13.4 \mu \mathrm{m})$ show a similar dynamic range and

similar shape of the histograms, with good agreement in the positioning of the distribution maximum. Nevertheless, some small differences are noticeable around 275 and $285 \mathrm{~K}$ for the $10.8-$ and $12.0-\mu \mathrm{m}$ channels, possibly indicating slight differences in the morphology of some low clouds. In addition, there is a very minor underestimation in the frequency of occurrence for the warmest BTs between 0800 and 1500 UTC in the longwave window channels in the simulation (Fig. 4, top row; note that the logarithmic color scale emphasizes this effect). This result is related to deficiencies in 

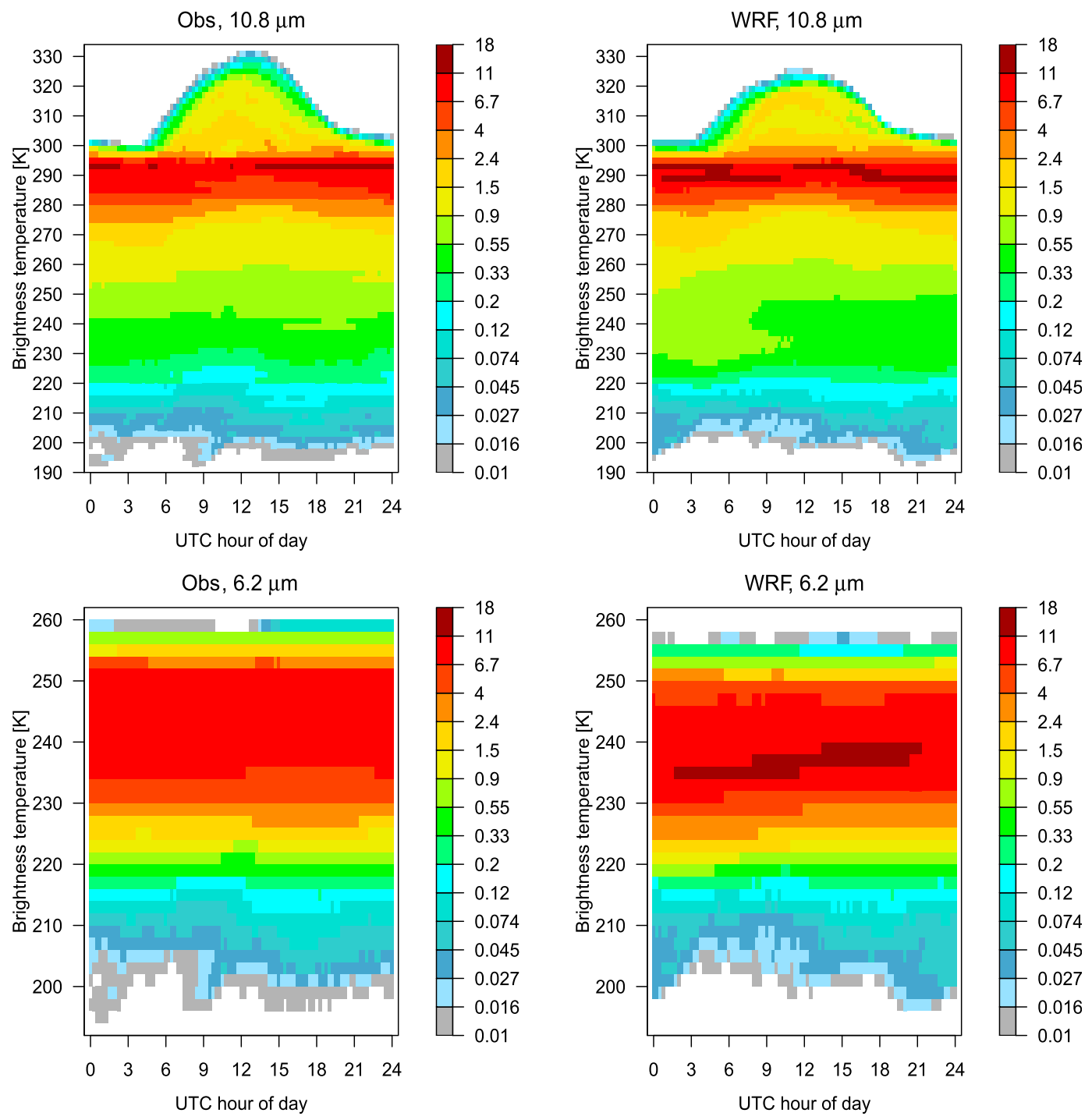

FIG. 4. Frequency distribution (\%) of BTs for the (bottom) 6.2- and (top) 10.8- $\mu \mathrm{m}$ channels, as a function of the time of day, for the (right) simulated images and (left) observed images. Statistics are shown for each time step, based on all pixels with a satellite zenith angle of less than $70^{\circ}$, within the latitude range of the WRF model. The bin size is $2 \mathrm{~K}$.

the modeling of the surface emissivity and the diurnal cycle of skin temperature in clear-sky regions over land. Some adjustments in the BT distributions are noticeable during the first $9-12 \mathrm{~h}$ of the study period (e.g., around the 230-240-K BT range), related to the overestimation of cirrus clouds during the spinup phase noted earlier (Fig. 4).

For the water-vapor channels at 6.2 and $7.3 \mu \mathrm{m}$, a cold bias is apparent, in particular for the higher-peaking $6.2-\mu \mathrm{m}$ channel, whereas the overall shapes of the BT distribution curves are again similar for the simulated and the observed images. A similar bias has been noted in Otkin et al. (2009) with a different radiative transfer model and linked to an overestimation of water vapor in the upper troposphere in the initialization of the WRF simulation. Such a bias is not present in similar statistics obtained from ECMWF fields (not shown), further suggesting that it is a feature of the WRF data, rather than the radiative transfer model. As can be seen in Fig. 4 , the bias is strongest during the first $9-12 \mathrm{~h}$ of the study period, as the model adjusts to more realistic levels during its spinup phase.

\section{c. Spatial and temporal variability}

Maps of the standard deviation of the BT time series show similar levels of temporal variability in the simulated 

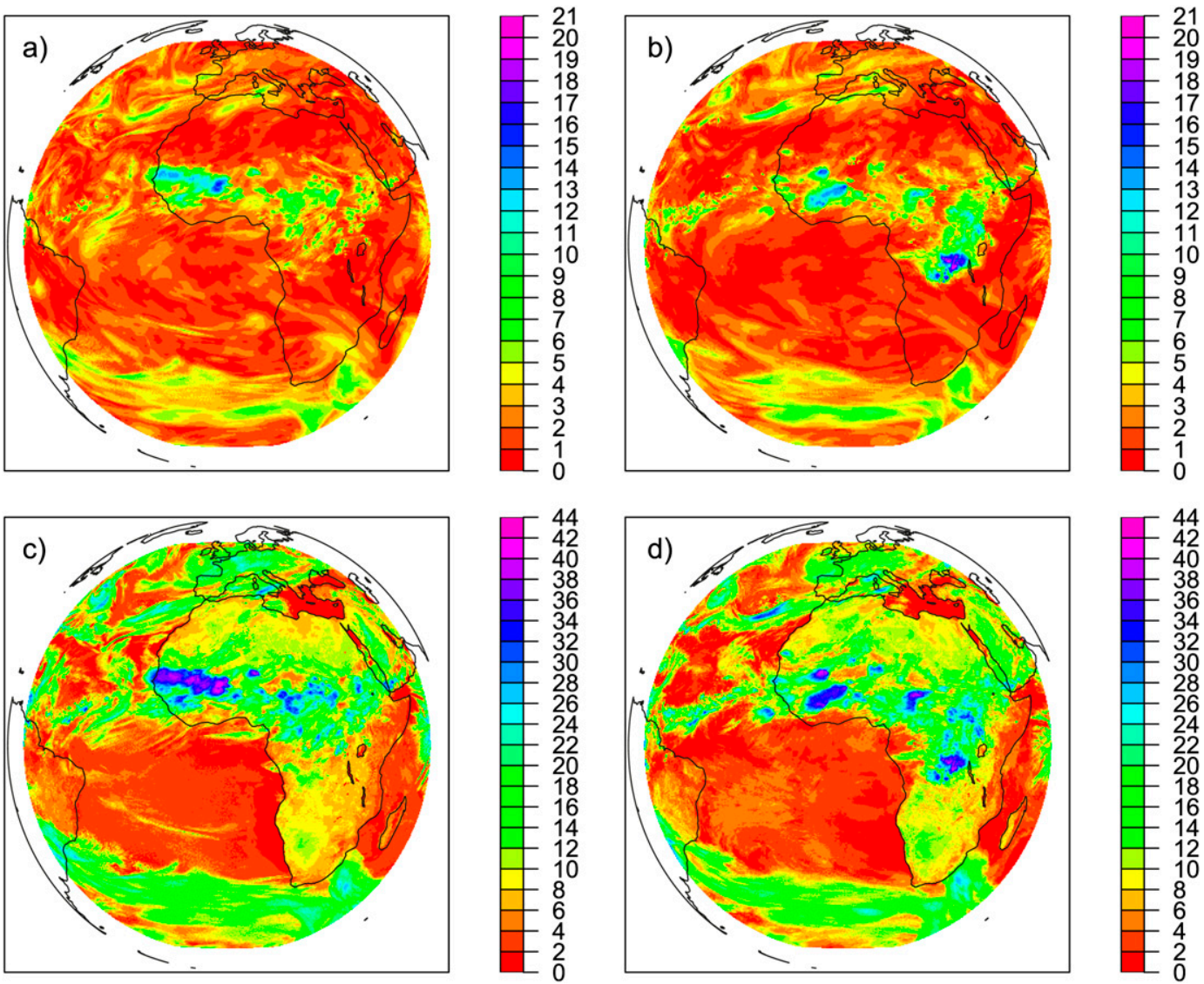

FIG. 5. Standard deviation of the time series of BT (K) for the $6.2-\mu \mathrm{m}$ channel from the (a) simulated imagery and (b) observed imagery and for the 10.8- $\mu \mathrm{m}$ channel from the (c) simulations and (d) observed imagery. Only alternate time steps have been selected for the time series, and only every eighth pixel is shown.

and observed imagery (Fig. 5). This is also true for the intertropical convergence zone even though some differences in the location of the maxima are apparent. As noted earlier, such location differences are of lesser concern in this study.

The effective resolution or spatial variability of the images has also been analyzed, because it is of relevance to the success of the AMV tracking algorithm. The measure of the effective resolution follows the approach previously used by Chevallier and Kelly (2002), and it is defined as follows: for each pixel, we determine the smallest distance at which the correlation between the time series of BTs of a given pixel and those of all nearby pixels drops below a given threshold. That is, the measure quantifies the scales at which the BT shows significant variability. After some experimentation we chose 0.9 as the correlation threshold; lower values tend to lead to larger estimates of the effective resolution but qualitatively similar results. Note that here the effective resolution is calculated on a pixel-by-pixel basis over 1-day time series of BTs, whereas Chevallier and Kelly (2002) considered larger spatial averages over a much longer period. Our estimates of the effective resolution are therefore not comparable to those of Chevallier and Kelly (2002).

Given that our time series are relatively short, we found that the pixel-by-pixel estimates of the effective resolution depend on the standard deviation of the BTs for the given pixel over the study period. Pixels with low standard deviations lead to unreliable estimates of the effective resolution, because the calculation involves the division by a value close to 0 . We hence present our results in terms of two-dimensional histograms of the number of pixels exhibiting a certain standard deviation and effective resolution, excluding cases with standard deviations that are too low (Fig. 6).

The WRF images show effective resolution-standard deviation relationships that compare well to those obtained from the observed images (e.g., Fig. 6). Both show effective resolution peaks in the two-dimensional histograms around $10-15 \mathrm{~km}$. This result further demonstrates that the spatial variability of the clouds 

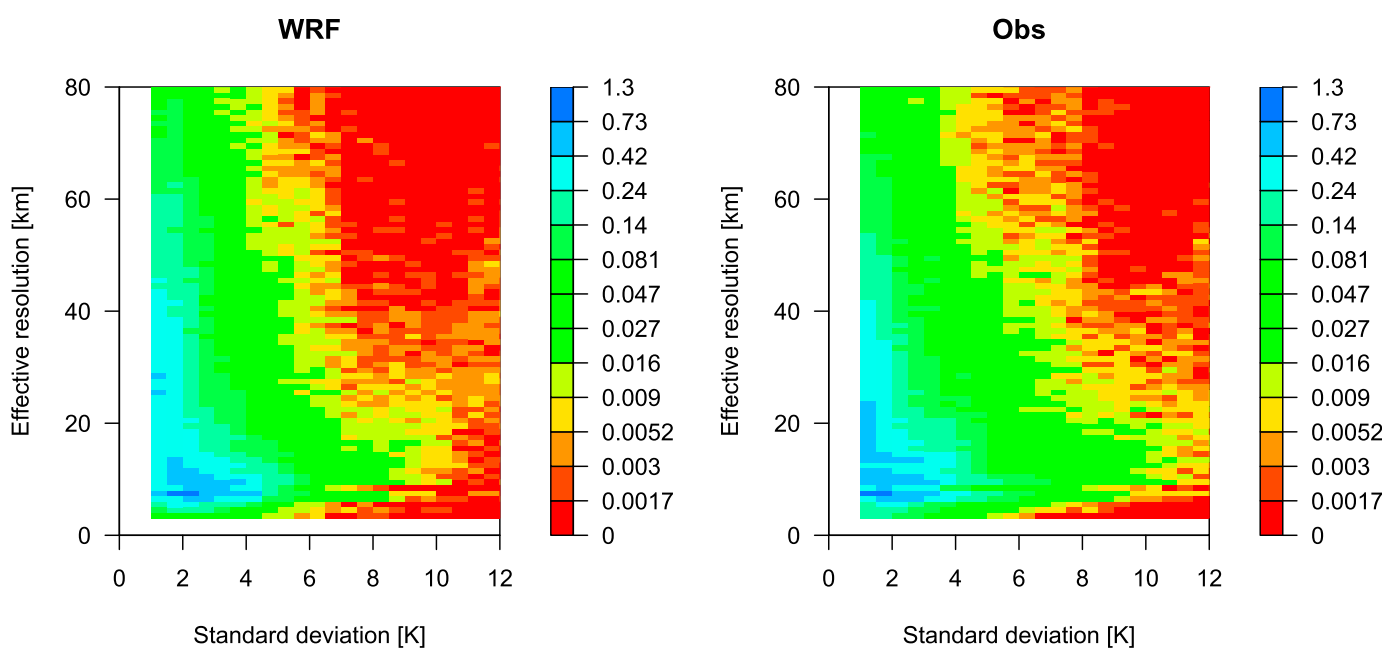

FIG. 6. Two-dimensional histograms of the percentage of pixels with a given standard deviation of BTs/effective resolution for the $6.2-\mu \mathrm{m}$ channel for the (left) simulation results and (right) observed distribution.

represented in the simulated imagery is, overall, consistent with the observed images, an important prerequisite for comparable feature tracking.

In summary, the simulated imagery agrees well with characteristics of observed imagery, both in terms of the general distribution of clouds and the effective spatial resolution. Nevertheless, adjustments related to the spinup of the simulation have been identified for the first 9-12 $\mathrm{h}$ of the study period, and there is an indication of a bias for upper-tropospheric humidity. Within this context, it is worth mentioning that we have performed the same analysis with a 10-km-resolution setup of the ECMWF model, similar to that used in von Bremen (2008). This analysis clearly revealed a lower effective resolution of the simulated data when compared with observed imagery, as well as a very notable underestimation of low brightness temperatures associated with high clouds (not shown). We therefore think that this study provides a significantly enhanced image simulation when compared with that of von Bremen (2008).

\section{Evaluation of single-level AMVs versus model truth}

We now present a comparison of the simulated AMVs with the model truth. This comparison follows the traditional interpretation of AMVs as single-level point estimates of wind, as is currently standard practice in NWP. To do so, the model wind is interpolated to the AMV location and assigned pressure level by linear interpolation of the model fields both horizontally and in the vertical direction.

For comparison, we also provide statistics for AMVs derived from observed images. Two different sets are considered here: the AMVs derived with the EUMETSAT prototype system used in this study and AMVs that were derived operationally at EUMETSAT at the time (16 August 2006). The former were unfortunately only available for four time slots for our study period (0600, 1200,1400 , and 1800 UTC), allowing only a limited direct assessment. The operational AMVs were available hourly for the full day. The most notable difference between the two derivation systems is the use of the CCC method together with the CLA cloud-top pressure in the prototype system (see also section $2 \mathrm{c}$ ), whereas a clustering scheme and a height assignment tailored to AMVs were used in the operational system. For further details on the operational EUMETSAT processing, the reader is referred to Schmetz et al. (1993) and Holmlund (2000).

The AMVs derived from observed images are compared with short-range operational forecasts from ECMWF's global assimilation system. Note that the comparison between the real AMVs and the ECMWF short-range forecasts includes a component of forecast error, whereas that component is eliminated by design in the comparison between simulated winds and the model truth. The comparison between AMVs and the short-range forecasts are therefore expected to show larger root-mean-square vector differences (RMSVDs) than the comparison between the simulated winds and the truth.

For all three datasets we only consider AMVs with a model-independent QI $>80 \%$, this threshold being a common choice for monitoring AMVs (e.g., Cotton and Forsythe 2012). The QI is calculated on the basis of temporal and spatial consistency of the derived wind field, as further described in Holmlund (1998). Although 
TABLE 1. Summary statistics for high-level (100-400 hPa) WV AMVs for the four time slots (0600, 1200, 1400, and 1800 UTC), grouped by Northern Hemisphere (NH), tropics (TR), and Southern Hemisphere (SH) as in Fig. 1. Results are shown for the WRF AMVs ("WRF," in comparison with the model truth), the WRF AMVs after the pressure adjustment ("WRF bcor," with a global pressure offset of $60 \mathrm{hPa}$ ), and AMVs derived from observed images with the prototype system used in this study ("Obs proto," in comparison with shortrange forecasts) and from operations at the time ("Obs ops," also compared with short-range forecasts). Only winds with a modelindependent QI $>80 \%$ have been used, and outliers with a vector difference larger than $20 \mathrm{~m} \mathrm{~s}^{-1}$ have been removed. The statistics follow the format proposed in Menzel (1996).

\begin{tabular}{|c|c|c|c|c|c|c|c|c|c|c|c|c|}
\hline & \multicolumn{4}{|c|}{$\mathrm{NH}$} & \multicolumn{4}{|c|}{ TR } & \multicolumn{4}{|c|}{$\mathrm{SH}$} \\
\hline & WRF & $\begin{array}{l}\text { WRF } \\
\text { bcor }\end{array}$ & $\begin{array}{l}\text { Obs } \\
\text { proto }\end{array}$ & $\begin{array}{l}\text { Obs } \\
\text { ops }\end{array}$ & WRF & $\begin{array}{l}\text { WRF } \\
\text { bcor }\end{array}$ & $\begin{array}{l}\text { Obs } \\
\text { proto }\end{array}$ & $\begin{array}{l}\text { Obs } \\
\text { ops }\end{array}$ & WRF & $\begin{array}{l}\text { WRF } \\
\text { bcor }\end{array}$ & $\begin{array}{l}\text { Obs } \\
\text { proto }\end{array}$ & $\begin{array}{l}\text { Obs } \\
\text { Ops }\end{array}$ \\
\hline No. & 1356 & 1242 & 1550 & 1844 & 2993 & 3105 & 2748 & 4183 & 3280 & 3177 & 3471 & 3434 \\
\hline Speed bias $\left(\mathrm{m} \mathrm{s}^{-1}\right)$ & -2.5 & -0.2 & -0.2 & 0.2 & -1.2 & -0.2 & 0.5 & 1.1 & -2.8 & 0.3 & -0.4 & -0.2 \\
\hline AMV speed $\left(\mathrm{m} \mathrm{s}^{-1}\right)$ & 21.6 & 21.9 & 25.7 & 22.7 & 13.7 & 14.0 & 14.5 & 12.7 & 38.5 & 38.2 & 42.2 & 40.3 \\
\hline $\operatorname{RMSVD}\left(\mathrm{m} \mathrm{s}^{-1}\right)$ & 7.2 & 5.8 & 5.7 & 5.7 & 9.5 & 6.5 & 5.6 & 6.6 & 8.3 & 6.0 & 7.3 & 7.2 \\
\hline $\operatorname{NRMSVD}\left(\mathrm{m} \mathrm{s}^{-1}\right)$ & 0.33 & 0.26 & 0.22 & 0.25 & 0.70 & 0.47 & 0.39 & 0.52 & 0.22 & 0.16 & 0.18 & 0.18 \\
\hline
\end{tabular}

there are some differences in the calculation of the QI provided in the datasets, the resulting statistics suggest that the distribution of AMVs as a function of QI and the general characteristics are consistent. A higher threshold would show higher quality at the expense of a reduced sample size.

The simulated winds show a considerable slow bias of several meters per second at high and midlevels over the extratropics, as well as relatively high RMSVDs and normalized RMSVDs (NRMSVDs), especially for the IR winds (see Tables 1 and 2). While slow speed biases at high levels in the extratropics are a common feature with AMVs, the speed bias and the RMSVD for the simulated data are larger than for the observed AMVs from both derivation systems.
Further investigations show that these poorer statistics are largely due to a significant bias in the height assignment for the simulated AMVs. This is very clearly seen in Fig. 7, which summarizes comparisons between the assigned pressure and the best-fit pressure level (LBF) for the simulated and observed AMVs. To calculate the best-fit pressure, each AMV is compared with the entire model wind profile interpolated to the AMV location, and the best-fit pressure is the tropospheric pressure level with the lowest vector difference. For the simulated AMVs there is a clear shift in the histograms of the differences between the assigned pressure and the LBF relative to the observed AMVs. These statistics suggest that the bias in height assignment for the operational AMVs or the observed

TABLE 2. As in Table 1, but for IR AMVs. The global pressure offset for the WRF bcor column is $75 \mathrm{hPa}$.

\begin{tabular}{|c|c|c|c|c|c|c|c|c|c|c|c|c|}
\hline & \multicolumn{4}{|c|}{$\mathrm{NH}$} & \multicolumn{4}{|c|}{ TR } & \multicolumn{4}{|c|}{$\mathrm{SH}$} \\
\hline & WRF & $\begin{array}{l}\text { WRF } \\
\text { bcor }\end{array}$ & $\begin{array}{l}\text { Obs } \\
\text { proto }\end{array}$ & $\begin{array}{l}\text { Obs } \\
\text { ops }\end{array}$ & WRF & $\begin{array}{l}\text { WRF } \\
\text { bcor }\end{array}$ & $\begin{array}{l}\text { Obs } \\
\text { proto }\end{array}$ & $\begin{array}{l}\text { Obs } \\
\text { ops }\end{array}$ & WRF & $\begin{array}{l}\text { WRF } \\
\text { bcor }\end{array}$ & $\begin{array}{l}\text { Obs } \\
\text { proto }\end{array}$ & $\begin{array}{l}\text { Obs } \\
\text { ops }\end{array}$ \\
\hline \multicolumn{13}{|c|}{ High-level $(100-400 \mathrm{hPa})$} \\
\hline No. & 1861 & 1664 & 1445 & 1577 & 3531 & 3700 & 2379 & 2924 & 3567 & 3550 & 3057 & 2623 \\
\hline Speed bias $\left(\mathrm{m} \mathrm{s}^{-1}\right)$ & -2.9 & -1.4 & -1.1 & -0.3 & -2.5 & -0.7 & -0.1 & -0.1 & -3.7 & -0.1 & -2.1 & -0.8 \\
\hline AMV speed $\left(\mathrm{m} \mathrm{s}^{-1}\right)$ & 19.5 & 19.9 & 23.6 & 21.3 & 11.8 & 12.1 & 13.5 & 11.4 & 36.7 & 36.7 & 38.9 & 37.6 \\
\hline $\operatorname{RMSVD}\left(\mathrm{m} \mathrm{s}^{-1}\right)$ & 8.0 & 6.3 & 5.6 & 5.4 & 9.7 & 5.8 & 5.4 & 5.8 & 8.7 & 6.3 & 7.4 & 6.6 \\
\hline NRMSVD $\left(\mathrm{m} \mathrm{s}^{-1}\right)$ & 0.41 & 0.32 & 0.24 & 0.25 & 0.83 & 0.48 & 0.40 & 0.51 & 0.24 & 0.17 & 0.19 & 0.18 \\
\hline \multicolumn{13}{|c|}{ Midlevel $(400-700 \mathrm{hPa})$} \\
\hline No. & 411 & 504 & 338 & 280 & 1343 & 803 & 626 & 502 & 769 & 730 & 829 & 548 \\
\hline Speed bias $\left(\mathrm{m} \mathrm{s}^{-1}\right)$ & -3.8 & -1.5 & -2.9 & -0.4 & 1.4 & 0.44 & 1.5 & 1.2 & -6.0 & -3.3 & -3.7 & -2.5 \\
\hline AMV speed $\left(\mathrm{m} \mathrm{s}^{-1}\right)$ & 12.3 & 13.8 & 13.8 & 12.2 & 7.9 & 7.8 & 8.9 & 8.4 & 17.5 & 20.6 & 19.1 & 27.2 \\
\hline $\operatorname{RMSVD}\left(\mathrm{ms}^{-1}\right)$ & 6.8 & 6.3 & 6.4 & 4.5 & 6.5 & 5.6 & 5.8 & 4.4 & 10.0 & 8.6 & 8.4 & 7.4 \\
\hline NRMSVD $\left(\mathrm{m} \mathrm{s}^{-1}\right)$ & 0.55 & 0.46 & 0.46 & 0.37 & 0.83 & 0.72 & 0.65 & 0.53 & 0.57 & 0.42 & 0.44 & 0.27 \\
\hline \multicolumn{13}{|c|}{ Low level $(>700 \mathrm{hPa})$} \\
\hline No. & 799 & 940 & 512 & 774 & 7634 & 7979 & 5099 & 5889 & 2784 & 3043 & 1446 & 2208 \\
\hline Speed bias $\left(\mathrm{m} \mathrm{s}^{-1}\right)$ & -0.3 & -0.5 & 0.1 & 0.3 & 1.5 & 0.0 & 0.3 & 0.1 & 0.0 & -0.4 & 0.1 & 0.3 \\
\hline AMV speed $\left(\mathrm{m} \mathrm{s}^{-1}\right)$ & 8.3 & 9.1 & 8.7 & 10.2 & 9.0 & 9.0 & 8.8 & 8.6 & 9.4 & 10.1 & 9.8 & 9.4 \\
\hline $\operatorname{RMSVD}\left(\mathrm{m} \mathrm{s}^{-1}\right)$ & 3.4 & 2.8 & 3.1 & 2.8 & 4.8 & 2.5 & 3.7 & 3.3 & 4.5 & 3.2 & 3.4 & 2.5 \\
\hline NRMSVD $\left(\mathrm{m} \mathrm{s}^{-1}\right)$ & 0.41 & 0.31 & 0.35 & 0.27 & 0.54 & 0.28 & 0.42 & 0.39 & 0.47 & 0.31 & 0.35 & 0.26 \\
\hline
\end{tabular}



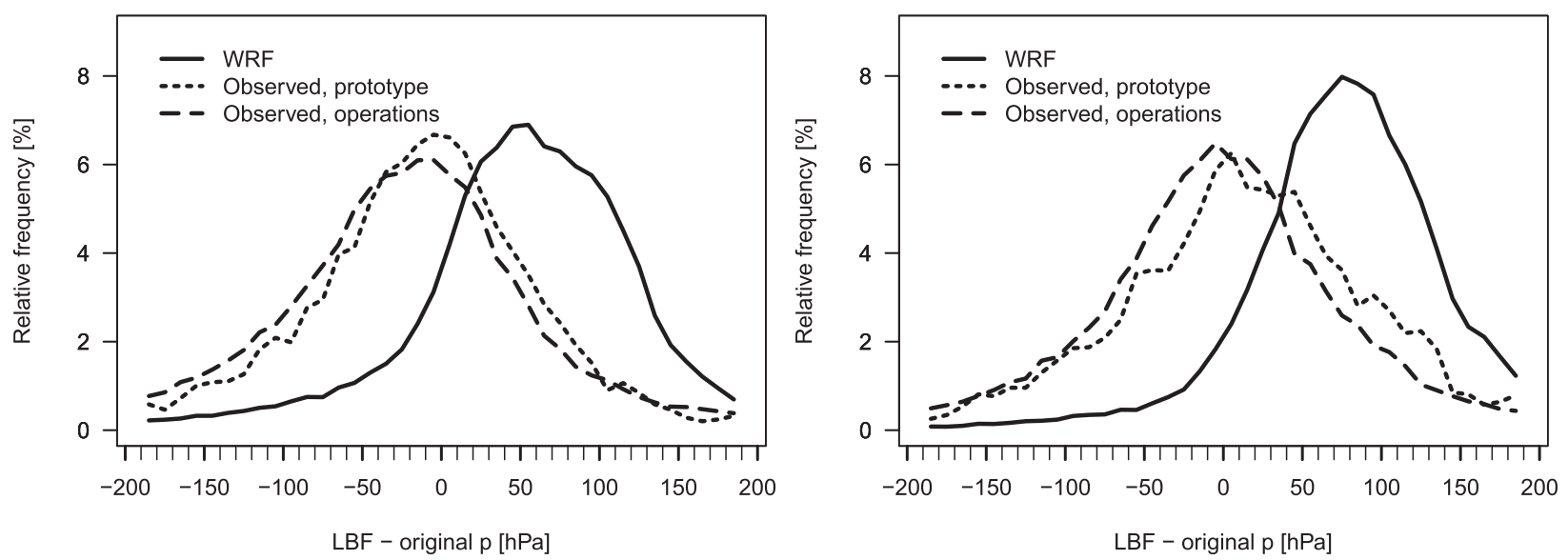

FIG. 7. Global histograms of the difference between the LBF and the originally assigned pressure (hPa) for (left) the WV and (right) the IR AMVs. Solids lines show statistics for the simulated AMVs, dotted lines are for the observed AMVs derived with the prototype system, and dashed lines are for the operational AMVs. Note that the statistics for the observed AMVs derived with the prototype system are based on the four time slots $(0600,1200,1400$, and $1800 \mathrm{UTC})$ only. The bin size is $10 \mathrm{hPa}$, and cases for which the LBF is associated with a very broad minimum in the RMSVD and hence is poorly determined are excluded.

AMVs derived with the prototype system is small, whereas there is a significant bias for the simulated AMVs. Note that this bias is in relation to the LBF and is not necessarily a bias in relation to the cloud top. The widths of the distributions shown in Fig. 7 are otherwise similar or slightly sharper for the simulated AMVs, suggesting that, aside from the bias, the height assignment for the simulated data is in line with the observed AMVs.

The reasons for such a height-assignment bias are not clear. It is likely the result of a number of factors, the investigation of which is beyond the scope of this study. The bias is likely to be linked to the upper-tropospheric humidity bias noted earlier in the BT distributions for the water vapor channels. The pressure bias may also be due to small differences in the bias characteristics in the simulated and observed images that are ignored in the height-assignment algorithm used in this study. Shortcomings in the representation of clouds in the WRF simulation or the radiative transfer calculations may also contribute; for high-level AMVs, the realism of semitransparent clouds will be particularly important in this respect.

To address the height-assignment bias, we consider here a simple pressure bias correction, which corrects IR and WV AMVs downward by 75 and $60 \mathrm{hPa}$, respectively. These values have been derived from Fig. 7 and are based on the median of the pressure and LBF differences. Further investigations show that the median values differ only slightly by geographical region and level (approximately $\pm 10 \mathrm{hPa}$; not shown), and therefore we decided to use one global value that differs only by channel. In the following, the adjusted pressure level will also be used to allocate the AMV to the standard pressure ranges used, for instance, in Tables 1 and 2. If the reassigned pressure is below the WRF surface pressure after the pressure bias correction, the AMV in question is ignored. Note that Fig. 7 also suggests a small bias for the observed AMVs with respect to the LBF of around $5-20 \mathrm{hPa}$. This effect is considered to be small, and we have not corrected for this bias in the observed AMVs. This approach favors the simulated AMVs, for which this bias has been removed. We have estimated the effect of this situation to be less than $0.1-0.2 \mathrm{~m} \mathrm{~s}^{-1}$ in terms of RMSVD and, at most, $0.5 \mathrm{~m} \mathrm{~s}^{-1}$ in terms of the speed bias.

After the bias correction, the speed biases and the RMSVD values are improved considerably, and now the statistics from the simulated dataset and the observed AMVs are more similar (Tables 1 and 2). For all levels and regions considered, the RMSVD for the bias-corrected simulated AMVs against the model truth now either is less than that for the real AMVs from the prototype system monitored against short-range forecasts or is within $1 \mathrm{~m} \mathrm{~s}^{-1}$. Speed biases for the bias-corrected simulated AMVs are also within $1 \mathrm{~m} \mathrm{~s}^{-1}$ of the values for the real AMVs derived either with the prototype or the operational system.

For the real AMVs, the above statistics include a component of forecast error (typically around $1-2.5 \mathrm{~m} \mathrm{~s}^{-1}$, depending on level), whereas the statistics for the simulated AMVs represent only the error in the AMVs. This aspect has to be taken into account when comparing the statistics for the simulated and the real AMVs. It suggests that, while for some areas the errors in the simulated AMVs are comparable to those for real AMVs 
(e.g., IR at low levels), for certain other regions and levels the errors in the simulated AMVs are larger than those for real AMVs (e.g., for IR AMVs at high levels over the Northern Hemisphere). Note here that RMSVDs against short-range forecasts frequently vary by around $\pm 2 \mathrm{~m} \mathrm{~s}^{-1}$ on daily time scales for high levels, primarily as a result of geographical sampling of the AMVs. Within this day-to-day variability of AMV quality, the statistics suggest that the simulated AMVs reproduce general characteristics of real AMVs, and the error statistics are approaching those of real AMVs. The current simulation study is therefore considered to be a useful benchmark to further investigate the characteristics of current AMVs.

Comparing the statistics for the real AMVs from the prototype system with those from operations highlights the differences that arise from using a different derivation algorithm, with the prototype system performing better than operations at the time in some areas and performing worse in others (most notably low-level AMVs).

Two-dimensional histograms of the AMV and model wind speed and direction show that the distributions after the bias correction are approximately symmetric around the diagonal, and hence errors in speed and direction in the AMVs are also approximately symmetric (Figs. 8 and 9). The simulated AMVs show a somewhat higher tendency for outliers than do the observed AMVs, both for speed and direction (see, e.g., the cases of low AMV speed but large model wind speed at high levels in Fig. 8). Note that such outliers have been removed for the statistics presented in Tables 1 and 2 for all datasets, by requiring the vector difference to be within $20 \mathrm{~m} \mathrm{~s}^{-1}$ (approximately 3 times the RMSVD for high and midlevels). This technique ensures that the statistics are not dominated by a few outliers; in the case of the bias-corrected simulated AMVs this criterion typically rejects less than $2 \%$ of the considered AMVs. Two-dimensional direction histograms reveal a tendency for the simulated AMVs to favor certain directions. The feature is most prominently seen for regions of low wind speed and when selecting winds with a high QI (see, e.g., the vertical striping in Fig. 9). The striping is not present in the set of AMVs from operations. Further investigations suggest that this aspect is a feature of the prototype AMV derivation system and is related to the discretization of values for the $u$ and $v$ components introduced through the pixel size of the image and the time interval between images. Methods exist to minimize this effect, but they are ineffective in the prototype system. Although the feature is suboptimal for the prototype system, the monitoring statistics for the prototype and the operational AMVs suggest that it is not a major limitation (Tables 1 and 2).

To assess the impact of the spinup noted earlier for the first $9-12 \mathrm{~h}$ of the study period, the presented statistics were also calculated separately for the first and second halves of the study period. The differences for the two periods are relatively small (global speed biases and RMSVDs are within $0.5 \mathrm{~m} \mathrm{~s}^{-1}$, without clear preference for the first or second half), suggesting that the spinup has only a small effect on the AMV quality characteristics.

\section{Error correlations for simulated AMVs}

Error correlations between different AMVs are an unavoidable feature, because errors in the height assignment, the background data used in the winds derivation, the interpretation of the AMVs, the quality control, or the spatial representativeness may all be correlated spatially, vertically, or temporally. For instance, Bormann et al. (2003) investigated spatial error correlations in real AMVs and found significant correlations on scales of several hundreds of kilometers, with broader correlations over the tropics than over the extratropics. Similar findings have been reported by Berger et al. (2006) and Bonavita and Torrisi (2006). To our knowledge, temporal or vertical error correlations for real AMVs have not yet been quantified.

Knowledge about error correlations is relevant to the assimilation of AMVs, because the presence of error correlations affects important data assimilation parameters such as the setting of observation errors and data selection/thinning scales. The operational assimilation of AMVs currently neglects error correlations and instead uses spatial thinning (scales of $140 \mathrm{~km}$ at ECMWF) and inflated observation errors. Liu and Rabier (2002) showed that using data with correlated errors too densely while assuming uncorrelated errors can result in a worse analysis than when data are thinned. They found optimal thinning scales given by separations at which the error correlations fall below 0.2. Isaksen and Radnóti (2010) developed methods to take some of the effects of error correlations explicitly into account in data assimilation and applied these to AMVs with mixed success. Experimentation with error correlations would be helped by a better specification of the correlation scales, especially for vertical and temporal error correlations.

\section{a. Method}

Here, we calculate spatial as well as temporal and vertical error correlations from the simulated AMVs. This calculation is straightforward in the simulation 
WRF WV AMVs, Tropics, high level

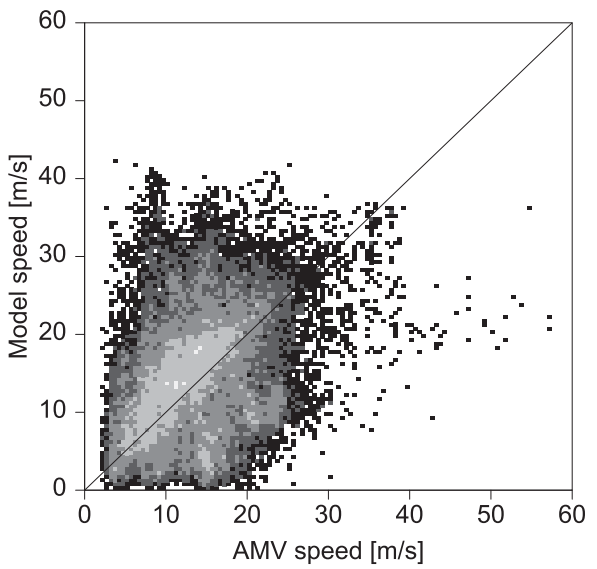

WRF WV AMVs bcor, Tropics, high level
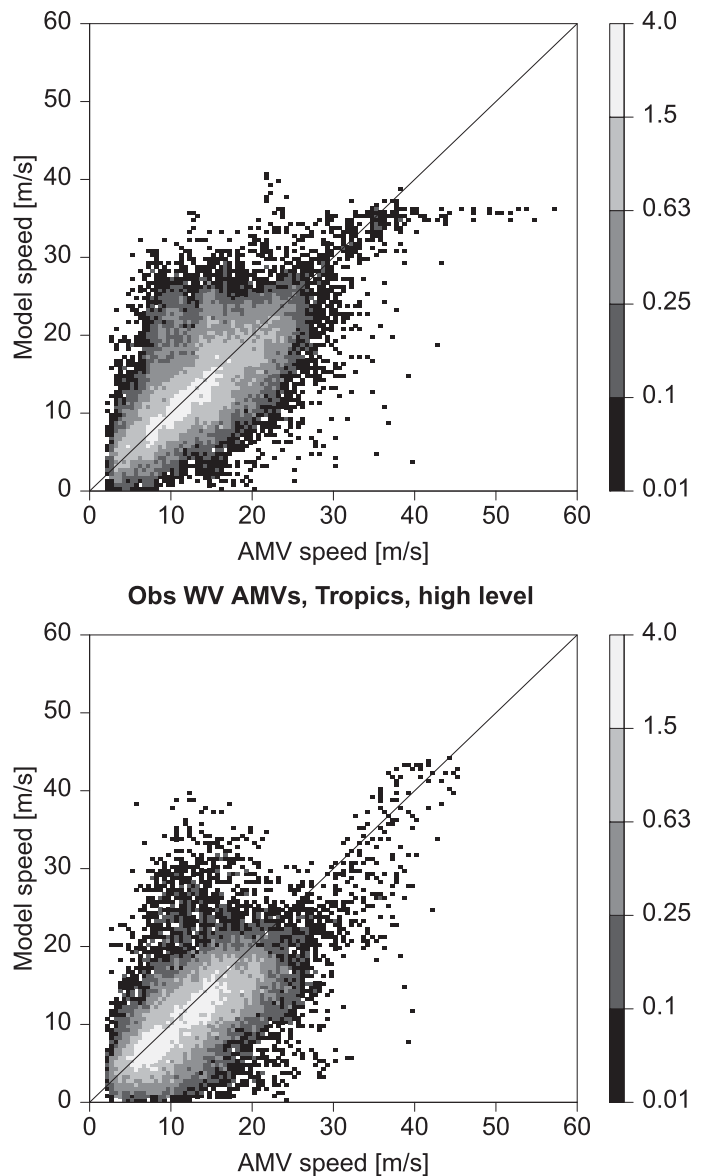

WRF WV AMVs, S.Hem, high level
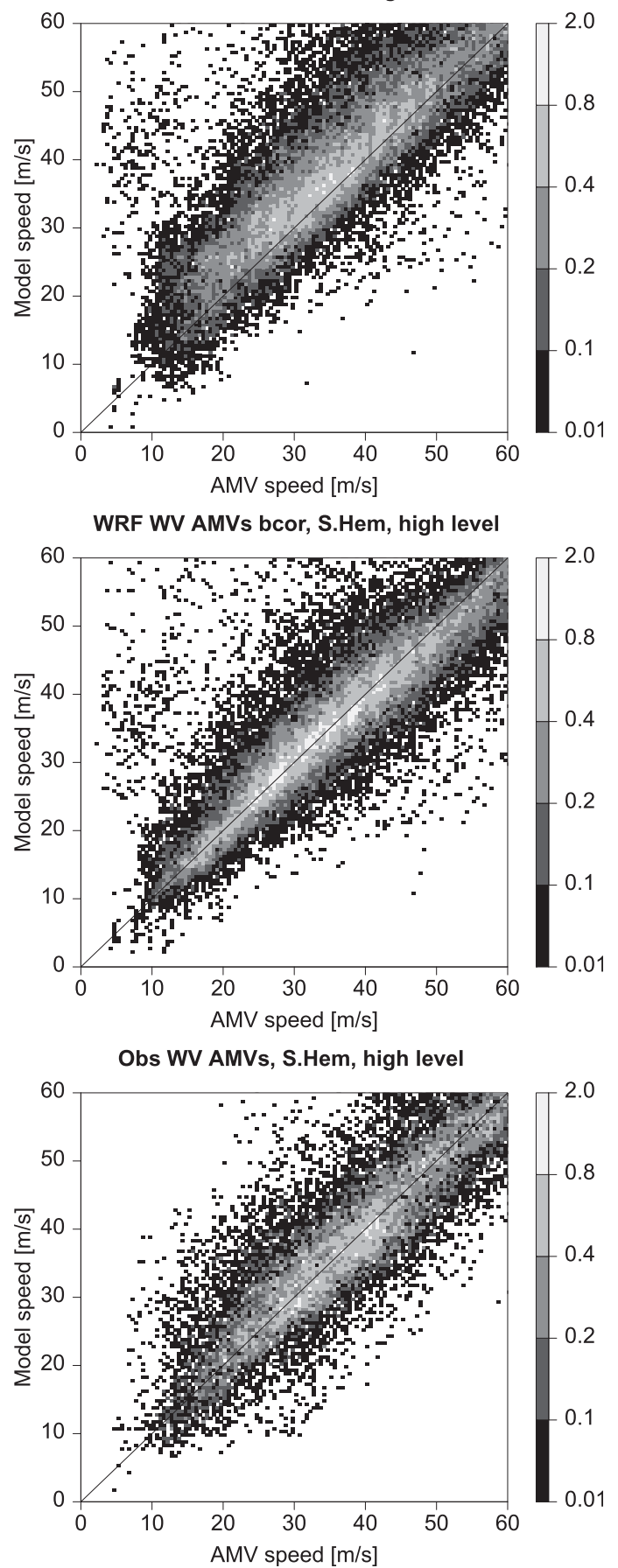

FIG. 8. Two-dimensional histograms of AMV and model speed for high-level WV AMVs (100-400 hPa), from simulated imagery (top) before and (middle) after the pressure bias correction, as well as (bottom) from operations at the time of the study period, for the (left) tropics and (right) Southern Hemisphere extratropics. The shading indicates the fraction of AMVs $(\%)$ per $0.5 \mathrm{~m} \mathrm{~s}^{-1}$ bin relative to the number of AMVs in the considered region.

framework, because the differences between AMVs and the model truth are readily available. As in the previous section, we treat the AMVs as single-level point measurements. Given the significant height-assignment bias discussed above, we use the simulated AMVs after the pressure bias correction introduced in the previous section. Also, throughout this investigation a QI threshold of $80 \%$ has been applied to screen out poor-quality 

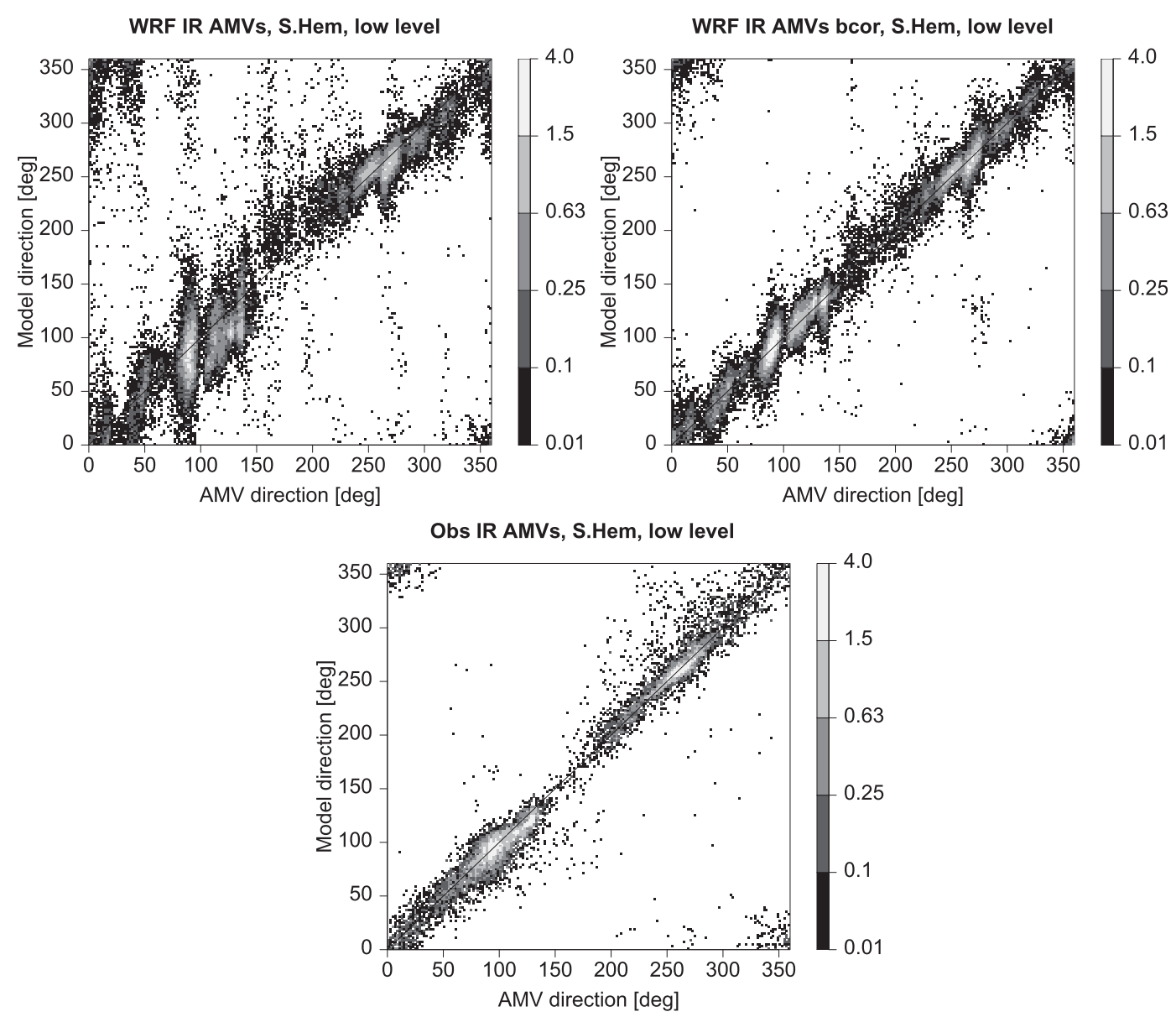

FIG. 9. Two-dimensional histograms of AMV and model direction for low-level IR AMVs ( $>700 \mathrm{hPa})$ from simulated imagery (top left) before and (top right) after the pressure bias correction, as well as (bottom) from operations at the time of the study period for the Southern Hemisphere extratropics. The shading indicates the fraction of AMVs $(\%)$ per $2^{\circ}$ bin relative to the number of AMVs in the considered region.

AMVs, and outliers are removed by requiring a vector difference of less than $20 \mathrm{~m} \mathrm{~s}^{-1}$.

The calculations are based on a set of pairs of differences between AMVs and the model truth. This set has been produced by pairing up each simulated AMV with all other available AMVs (subject to certain criteria; see below). Spatial, temporal, and vertical error correlations have been calculated by binning the AMV pairs into suitable spatial, temporal, and vertical distance intervals. For spatial correlations, only isotropic correlations are considered here (i.e., those that depend only on the distance between the two pairs). Large-scale geographical biases have been removed by subtracting the mean error for each geographical region/layer shown. Table 3 shows the criteria used to pair up and bin the AMVs to focus on spatial, temporal, and vertical correlations.

As in Bormann et al. (2003), we will show only the average between the correlations for the $u$ and $v$ components, because they are most isotropic and most relevant to NWP. For spatial error correlations, an analytical function is fitted to the correlation relationship, primarily to aid the comparison with results presented in Bormann et al. (2003). As in Bormann et al. (2003), the chosen function is the second-order autoregressive (SOAR) function, with

$$
R(r)=R_{0}\left(1+\frac{r}{L}\right) e^{-r / L},
$$

where $R_{0}$ indicates the proportion of the spatially correlated part of the error and $L$ is a length scale. Note that for the chosen function $R(L)=2 R_{0} / e$ and not $R_{0} / e$ as for many other correlation functions. The SOAR fit to the correlation/distance relationship has been calculated by minimizing the sum of the squared differences, weighted by the number of AMV pairs available for each bin. The value at zero distance is excluded, to allow for the possibility of a spatially uncorrelated error. 
TABLE 3. Matching and binning parameters used to obtain the error correlation data.

\begin{tabular}{lcc}
\hline \hline $\begin{array}{c}\text { Type of } \\
\text { correlation }\end{array}$ & Criteria to match pairs & $\begin{array}{c}\text { Binning } \\
\text { interval }\end{array}$ \\
\hline Spatial & $\begin{array}{c}\text { Temporal: same valid time; vertical: } \\
\text { less than } 50 \mathrm{hPa} \text { apart }\end{array}$ & $50 \mathrm{~km}$ \\
Vertical & $\begin{array}{c}\text { Temporal: same valid time; spatial: } \\
\text { less than } 100 \mathrm{~km} \text { apart }\end{array}$ & $50 \mathrm{hPa}$ \\
Temporal & $\begin{array}{c}\text { Spatial: less than } 100 \mathrm{~km} \text { apart; } \\
\text { vertical: less than } 50 \mathrm{hPa} \text { apart }\end{array}$ & $1 / 2 \mathrm{~h}$ \\
\hline
\end{tabular}

\section{b. Results}

There are significant spatial error correlations on scales of several hundreds of kilometers for the IR AMVs as well as the WV AMVs in the simulated dataset (Fig. 10). The error correlation scales are broader in the tropics for both types of winds (Table 4); for the IR winds, the error correlation scales are shortest for the high-level winds.

We will now compare our results from the SOAR fit with those presented for real data in Bormann et al. (2003, their Tables 2 and 3). Note that $R_{0}$ in Bormann et al. (2003) represented the spatially correlated part of AMV-radiosonde differences, whereas in our case it gives the actual proportion of the spatially correlated error, and therefore the two values should not be compared. A strict comparison for $L$ is also not possible, because Bormann et al. (2003) used a whole year of AMV data from all operational satellites at the time, and values for Meteosat- 8 are therefore not provided. Also, we found that the fit of the SOAR function to the correlation data for the simulated dataset is not always as good as it is in Bormann et al. (2003). This result may be an artifact of the limited sampling, or it might be that the errors found here show a different spatial structure.
The length scales from the SOAR fit agree relatively well with results presented in Bormann et al. (2003). Our study suggests values for $L$ of $110-220 \mathrm{~km}$ for high-level winds in the extratropics as compared with values of approximately $150-260 \mathrm{~km}$ for the real data and suggests values of $200-310 \mathrm{~km}$ for the tropics as compared with approximately $260-370 \mathrm{~km}$ for the real data. Overall, there is a tendency for the error correlations from the simulated AMVs to be sharper, possibly because correlations due to errors in the short-range forecast used in the height assignment are eliminated in our case or because of uncorrected overall height biases in the real AMVs. The values for the spatially correlated part of the error are typically $\sim 2.5-3.5 \mathrm{~m} \mathrm{~s}^{-1}$ for high-level winds, and the $v$ component shows smaller spatially correlated errors than the $u$ component. The estimates of the spatially correlated component are in the same range as estimates provided in Bormann et al. (2003).

Note that the values for $R_{0}$ indicate the presence of a nonnegligible error that is spatially uncorrelated (Table 4). Bormann et al. (2003) previously hypothesized that the spatially correlated error dominates and that the uncorrelated error is small. For the simulated winds it appears that the spatially uncorrelated error is of a comparable magnitude to the spatially correlated one.

The simulated AMVs show notable temporal error correlations, considering how often AMVs are typically provided (every 1-3h). The error correlations reach values of 0.2 at $\sim 4-8 \mathrm{~h}$ for high- and low-level winds (Fig. 11). The midlevel winds exhibit the broadest temporal error correlations, with error correlations reaching 0.2 at $8-18 \mathrm{~h}$, and these coincide with broad spatial error correlation scales as shown in Table 4. Similar to the spatial error correlations, there are indications of
N.Hem.

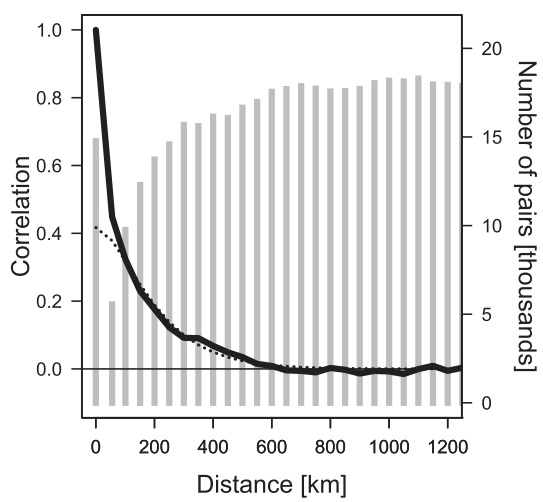

Tropics

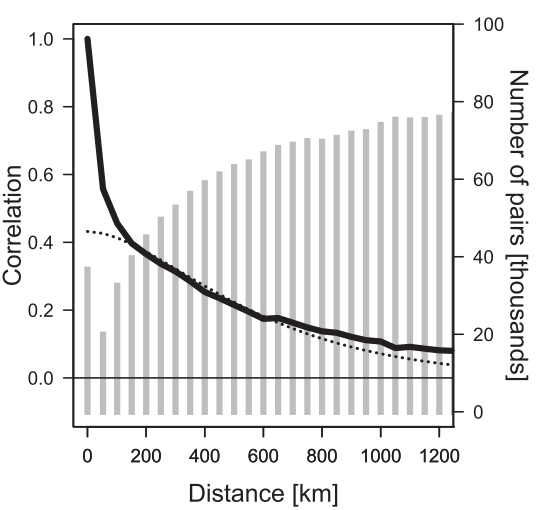

S.Hem.

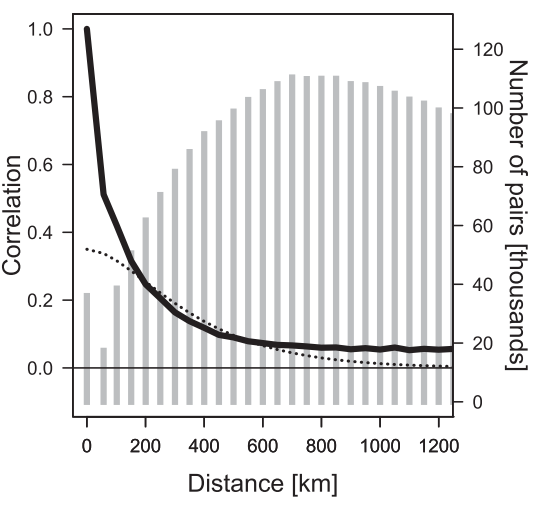

FIG. 10. Spatial error correlations for the high-level simulated WV AMVs (100-400 hPa; black solid lines) over the (left) Northern Hemisphere extratropics, (center) tropics, and (right) Southern Hemisphere extratropics. Also shown are the fits of the SOAR function (black dotted lines) and the number of AMV pairs used in each distance separation bin [vertical bars (in thousands; see right-hand $y$ axes)]. 
TABLE 4. Fitting parameters for the spatial error correlations obtained by fitting the SOAR function to the correlation data. Statistics are based on the simulated AMVs after adjusting for the pressure bias as described in the text. Also shown are $\sigma_{\text {cor }}$ and $\sigma_{\text {uncor }}$, the spatially correlated and uncorrelated parts of the AMV error, for $u$ and $v$, respectively. These have been obtained by partitioning the variance of the differences between AMVs and model truth at zero separation using the estimate of $R_{0}$. High, mid-, and low levels refer to the pressure bands at $100-400,400-700$, and $>700 \mathrm{hPa}$, respectively.

\begin{tabular}{|c|c|c|c|c|c|c|c|c|c|c|c|c|c|}
\hline & & \multicolumn{6}{|c|}{ IR winds } & \multicolumn{6}{|c|}{ WV winds } \\
\hline & & \multirow[b]{2}{*}{$R_{0}$} & \multirow[b]{2}{*}{$L(\mathrm{~km})$} & \multicolumn{2}{|c|}{$\begin{array}{c}\sigma_{\mathrm{cor}} \\
\left(\mathrm{m} \mathrm{s}^{-1}\right)\end{array}$} & \multicolumn{2}{|c|}{$\begin{array}{c}\sigma_{\text {uncor }} \\
\left(\mathrm{m} \mathrm{s}^{-1}\right)\end{array}$} & \multirow[b]{2}{*}{$R_{0}$} & \multirow[b]{2}{*}{$L(\mathrm{~km})$} & \multicolumn{2}{|c|}{$\begin{array}{c}\sigma_{\text {cor }} \\
\left(\mathrm{m} \mathrm{s}^{-1}\right)\end{array}$} & \multicolumn{2}{|c|}{$\begin{array}{c}\sigma_{\text {uncor }} \\
\left(\mathrm{m} \mathrm{s}^{-1}\right)\end{array}$} \\
\hline & & & & $u$ & $v$ & $u$ & $v$ & & & $u$ & $v$ & $u$ & $v$ \\
\hline \multirow[t]{3}{*}{$\mathrm{NH}$} & High level & 0.49 & 121 & 3.5 & 2.6 & 3.5 & 2.6 & 0.42 & 109 & 3.0 & 2.3 & 3.5 & 2.7 \\
\hline & Midlevel & 0.55 & 139 & 3.5 & 3.0 & 3.2 & 2.7 & - & - & - & - & - & - \\
\hline & Low level & 0.45 & 139 & 1.3 & 1.2 & 1.4 & 1.3 & - & - & - & - & - & - \\
\hline \multirow{3}{*}{ TR } & High level & 0.35 & 185 & 2.6 & 2.2 & 3.5 & 3.0 & 0.43 & 308 & 3.2 & 2.7 & 3.7 & 3.1 \\
\hline & Midlevel & 0.62 & 302 & 3.1 & 3.0 & 2.4 & 2.3 & - & - & - & - & - & - \\
\hline & Low level & 0.22 & 317 & 0.8 & 0.9 & 1.6 & 1.7 & - & - & - & - & - & - \\
\hline \multirow[t]{3}{*}{$\mathrm{SH}$} & High level & 0.35 & 208 & 3.0 & 2.5 & 4.1 & 3.4 & 0.35 & 195 & 2.8 & 2.4 & 3.8 & 3.3 \\
\hline & Midlevel & 0.62 & 326 & 4.9 & 3.9 & 3.9 & 3.1 & - & - & - & - & - & - \\
\hline & Low level & 0.22 & 316 & 1.1 & 0.9 & 2.1 & 1.8 & - & - & - & - & - & - \\
\hline
\end{tabular}

a significant temporally uncorrelated error for all levels considered. To our knowledge, these are the first estimates of temporal error correlations for AMVs.

Vertical error correlations are shown in Fig. 12. Here, we chose to combine the IR and WV winds to improve the available sample size. Note that, because only one AMV can be derived per segment from an image triplet from the same channel, the vertical error correlations are based on pairs of AMVs that are immediate neighbors or originate from tracking the same cloud structure in different channels. In the vertical direction, error correlations reach values of 0.2 for separations of $\sim 100 \mathrm{hPa}$. Again, these provide the first estimates of vertical error correlations for AMVs.
The error correlation statistics have also been calculated for the AMVs at their original height assignment, and in this case the correlated components of the error are much larger, mostly by $40-100 \%$. This result highlights how height-assignment biases can appear as a correlated error.

The above results suggest that error correlations are also present if AMVs are expressed in terms of speed and direction. All assimilation systems that we are aware of assimilate AMVs in terms of the $u$ and $v$ components, however, and therefore error correlations in terms of speed and direction are not discussed here.

The estimates for error correlations presented here are based on a single 24-h period and hence are based on
N.Hem.

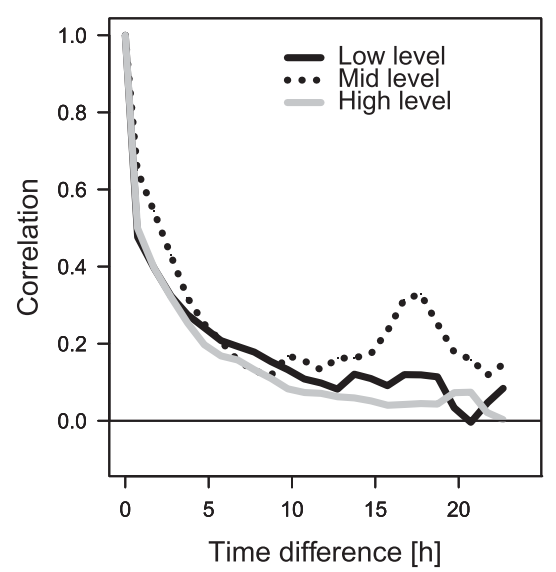

Tropics

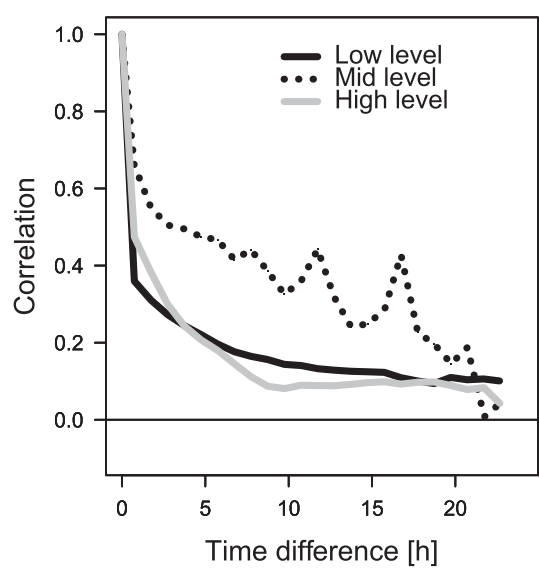

S.Hem.

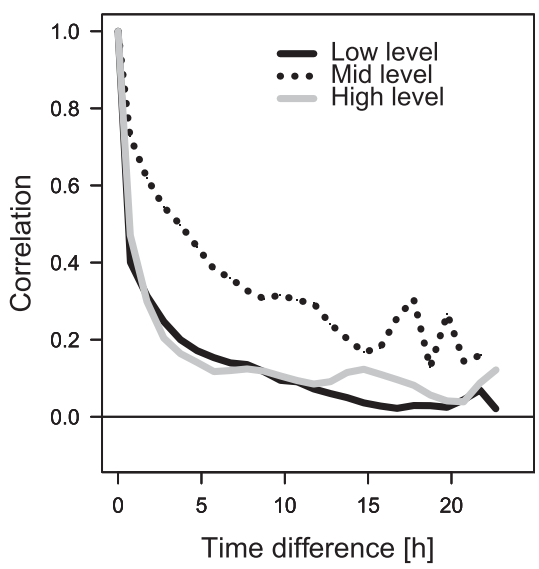

FIG. 11. Temporal error correlations for the simulated IR AMVs derived over the (left) Northern Hemisphere extratropics, (center) tropics, and (right) Southern Hemisphere extratropics for low ( $>700 \mathrm{hPa}$; black solid lines), middle (400-700 hPa; black dotted lines), and high (100-400 hPa; gray solid lines) levels. Note that the sample size of AMV pairs reduces almost linearly with time difference, given our 24-h study period. 
N.Hem.

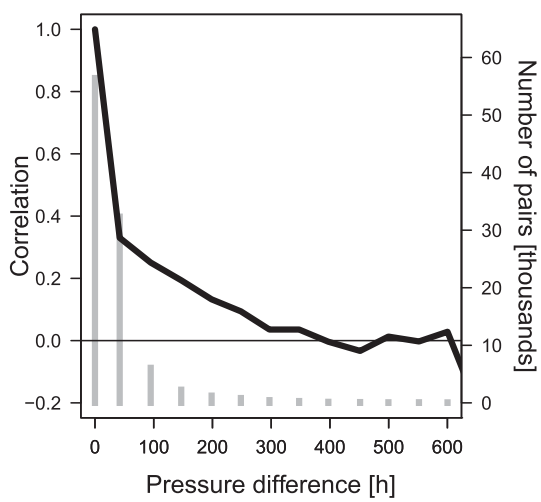

Tropics

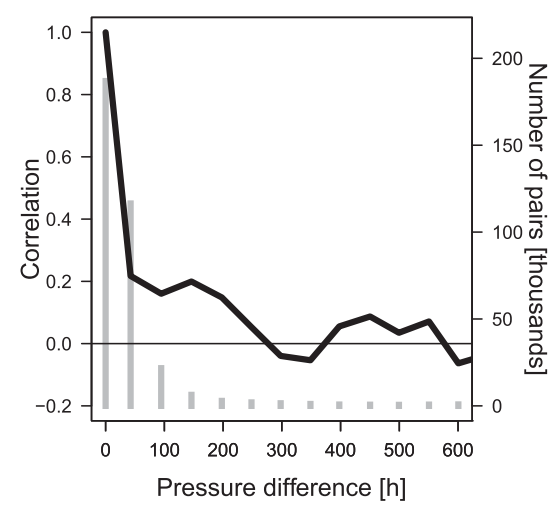

S.Hem.

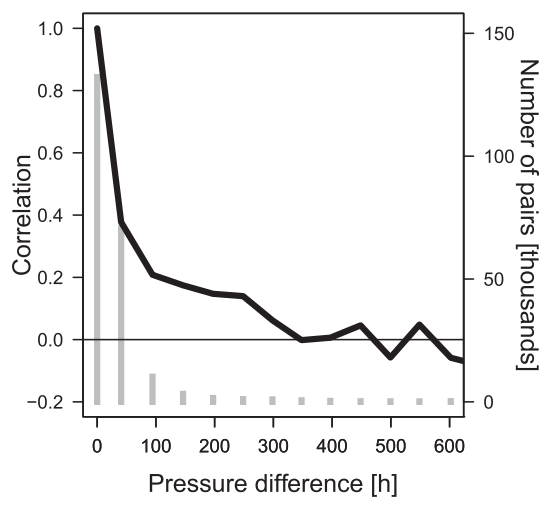

FIG. 12. Vertical error correlations for IR and WV AMVs combined (black solid lines) over the (left) Northern Hemisphere extratropics, (center) tropics, and (right) Southern Hemisphere extratropics. Also shown (as vertical bars) is the number of AMV pairs used in each distance separation bin (in thousands; see right-hand $y$ axes).

a relatively limited sample. Nevertheless, it is encouraging to see qualitative and quantitative agreement between our results and those for real data in terms of the error correlation scales for spatial error correlations. It suggests that the findings for the simulated data are likely to provide some indication for the presence of temporal and vertical error correlations in real AMVs, at least in a qualitative sense. Such error correlations are very difficult to obtain for real data, and the simulation framework may well be the only practical way to shed some light on these correlations.

\section{Conclusions}

This paper has presented the first part of a study whose main objective is to improve the understanding of the characteristics and origins of AMV errors, with the aim to improve the use of AMVs in NWP. The study uses a simulation framework that is based on AMVs derived from sequences of geostationary images that have been simulated from an integration of the WRF regional model. This paper (Part I) has introduced the simulation framework and given an initial analysis of the characteristics of the simulated imagery and the resulting AMVs. There are four main findings:

1) The general distribution of clouds in the simulated imagery appears to be realistic, with an effective resolution that matches well that of the observed imagery. Nevertheless, there is evidence that the simulation is still in a spinup phase during the first 9-12 h of the study period, and upper-tropospheric humidity appears to be overestimated.

2) The simulated AMVs exhibit a considerable heightassignment bias of $\sim 60-75 \mathrm{hPa}$, which is significantly larger than that for real AMVs. A bias correction for the assigned pressure is considered to be necessary for this simulated dataset.

3) When interpreted as single-level point estimates of wind at the bias-corrected pressure, the simulated AMVs when compared with the truth show characteristics that are similar to comparisons between real AMVs and short-range forecasts (e.g., speed biases and RMSVDs are typically within $1 \mathrm{~m} \mathrm{~s}^{-1}$ for highlevel AMVs). Taking into account that errors in the short-range forecasts contribute when comparing AMVs and short-range forecasts, the statistics suggest that the errors in the simulated AMVs are comparable to those for real AMVs over some areas and are larger in others. The simulated AMVs show more outliers than the real AMVs.

4) The simulated AMVs show significant horizontal, temporal, and vertical error correlations when they are interpreted as single-level values. The horizontal error correlation scales obtained here agree well with similar estimates from real AMVs, with nonnegligible error correlations for distances of $\sim 200-300 \mathrm{~km}$ in the extratropics and broader correlations in the tropics. For temporal and vertical error correlations, we find nonnegligible error correlations mostly in the range of $4-8 \mathrm{~h}$ and $100 \mathrm{hPa}$, respectively, depending on geographical region and level.

The current study serves as a benchmark for using a simulation framework to study AMV characteristics and errors. Such a simulation study is a very demanding computational undertaking, given the requirement for a high-resolution sophisticated atmospheric model, the need to store full model output at high temporal sampling with the associated handling of large amounts of data, and the costs of the radiative transfer simulations and the AMV derivation. It is hoped that future studies 
can build on the results presented here and further refine and improve the method and setups used. This study shows that a simulation framework can reproduce characteristics that are typically found in real AMVs, but it also highlights current shortcomings and shows that some errors in the simulated AMVs still appear to be larger than those in observed AMVs.

Our experience shows that a careful analysis of every step of the simulation is needed to interpret the results from the simulation study, and many aspects of our study still deserve further attention. Most notable is that the simulation-specific height-assignment bias requires further analysis in the future to relate it better to shortcomings in the WRF simulation, the radiative transfer calculations, or the height-assignment algorithm. In this study we investigated the realism of the simulated images by focusing on the general distribution of clouds and the effective resolution. Our experience suggests that this approach should be extended to other aspects that may affect the AMV derivation, such as the cloud optical depth and the emissivity of the simulated clouds. The finding that the errors in the simulated AMVs appear to be larger than those in the observed AMVs in some areas means that some care has to be taken when interpreting the results from this study for real data. Also, the results were obtained with a specific AMV derivation system, and, given that there are differences between different derivation systems, some of the characteristics found may well differ for other derivation algorithms.

Nevertheless, the simulation framework allows the study of aspects that are otherwise difficult or not possible because of the limited availability of collocated observations of winds and clouds. Here, we have used the simulation framework to provide the first estimates of temporal and vertical error correlation scales. Such error correlations are currently neglected in today's assimilation systems, and this fact may limit or penalize the impact of the assimilated AMVs. The current estimates provide guidance in this respect. Further investigations into the origin of the error correlations are possible with the simulated dataset-for instance, by experimenting with alternative AMV height interpretations.

This paper has used AMVs in the traditional way, interpreting them as estimates of wind at a single level, assumed to be the top of the tracked cloud structure. In Part II, we explore alternative interpretations of AMVs, making use of the detailed description of the atmosphere available in the simulation framework, including the known position of the tracked cloud in the vertical dimension.

Acknowledgments. We express our thanks to CIMSS for making the WRF simulation available for this study.
The study was funded by EUMETSAT Contract EUM/ CO/10/46000000785/RB. The WRF model simulation was performed on the cobalt supercomputer located at the National Center for Supercomputing Applications at the University of Illinois. Cobalt was part of the TeraGrid supercomputing network supported by the National Science Foundation. The comments from two anonymous reviewers helped to significantly improve the manuscript.

\section{REFERENCES}

Berger, H., C. Velden, and J. LeMarshall, 2006: New quality indicators for GOES derived winds and their potential effect on NWP data impact experiments. Proc. Eighth Int. Winds Workshop, Beijing, China, EUMETSAT, 7 pp. [Available online at http://www.eumetsat.int/groups/cps/documents/ document/pdf_conf_p47_s3_03_berger_v.pdf.]

Bonavita, M., and L. Torrisi, 2006: Characterization and use of MSG AMVs in the Italian Weather Service regional NWP system. Proc. Eighth Int. Winds Workshop, Beijing, China, Int. Satellite Winds Working Group, 9 pp. [Available online at http://www.eumetsat.int/groups/cps/documents/document/ pdf_conf_p47_s6_01_bonavita_v.pdf.]

Borde, R., and R. Oyama, 2008: A direct link between feature tracking and height assignment of operational atmospheric motion vectors. Proc. Ninth Int. Winds Workshop, Annapolis, MD, Int. Satellite Winds Working Group, 8 pp. [Available online at http://www.eumetsat.int/groups/cps/documents/ document/pdf_conf_p51_s3_13_borde_v.pdf.]

, A. D. Smet, G. Dew, P. Watts, H.-J. Lutz, M. Carranza, and M. Doutriaux-Boucher, 2011: AMV extraction scheme for MTG-FCI at EUMETSAT. Proc. 2011 EUMETSAT Meteorological Satellite Conf., Oslo, Norway, EUMETSAT, 10 pp. [Available online at http://www.eumetsat.int/groups/cps/ documents/document/pdf_conf_p59_s1_09_borde_v.pdf.]

Bormann, N., G. Kelly, and J.-N. Thépaut, 2002: Characterising and correcting speed biases in atmospheric motion vectors within the ECMWF system. Proc. Sixth Int. Winds Workshop, Madison, WI, Int. Satellite Winds Working Group, 113-120. [Available online at http://www.researchgate.net/publication/ 228491110_Characterising_and_correcting_speed_biases_in atmospheric_motion_vectors_within_the_ECMWF_system.]

_ S. Saarinen, G. Kelly, and J.-N. Thépaut, 2003: The spatial structure of observation errors in atmospheric motion vectors from geostationary satellite data. Mon. Wea. Rev., 131, 706-718.

Chevallier, F., and G. Kelly, 2002: Model clouds as seen from space: Comparison with geostationary imagery in the $11-\mu \mathrm{m}$ window channel. Mon. Wea. Rev., 130, 712-722.

Cotton, J., and M. Forsythe, 2012: Fifth analysis of the data displayed on the NWP SAF AMV monitoring website. Met Office Rep. NWPSAF-MO-TR-027, 42 pp. [Available online at http://research.metoffice.gov.uk/research/interproj/nwpsaf/ satwind_report/nwpsaf_mo_tr_027.pdf.]

Hernandez-Carrascal, A., and N. Bormann, 2014: Atmospheric motion vectors from model simulations. Part II: Interpretation as spatial and vertical averages of wind and role of clouds. J. Appl. Meteor. Climatol., 53, 65-82.

Holmlund, K., 1998: The utilization of statistical properties of satellite-derived atmospheric motion vectors to derive quality indicators. Wea. Forecasting, 13, 1093-1104. 
2000: The atmospheric motion vector retrieval scheme for Meteosat Second Generation. Proc. Fifth Int. Winds Workshop, Lorne, VIC, Australia, Int. Satellite Winds Working Group, 8 pp. [Available online at http://cimss.ssec.wisc.edu/ iwwg/iww5/S4-3_Holmlund-TheAtmospheric.pdf.]

Isaksen, L., and G. Radnóti, 2010: Accounting for atmospheric motion vector error correlations in the ECMWF 4D-VAR and ensembles of data assimilations. Proc. 10th Int. Winds Workshop, Tokyo, Japan, Int. Satellite Winds Working Group, 13 pp. [Available online at http://cimss.ssec.wisc.edu/iwwg/ iww10/talks/isaksen1.pdf.]

Kelly, G., R. Munro, M. Rohn, and K. Holmlund, 1998: Impact of atmospheric motion vectors (AMVs) on the ECMWF system and the development of a water vapour AMV observation operator. Proc. Fourth Int. Winds Workshop, Saanenmöser, Switzerland, Int. Satellite Winds Working Group, 13 pp. [Available online at http://cimss.ssec.wisc.edu/iwwg/iww4/ p125-137_Kelly-Impact.pdf.]

Liu, Z.-Q., and F. Rabier, 2002: The interaction between model resolution and observation resolution and density in data assimilation: A one-dimensional study. Quart. J. Roy. Meteor. Soc., 128, 1367-1386.

Matricardi, M., 2005: The inclusion of aerosols and clouds in RTIASI, the ECMWF fast radiative transfer model for the Infrared Atmospheric Sounding Interferometer. ECMWF Tech. Memo. 474, 53 pp. [Available online at http://www. ecmwf.int/publications/library/ecpublications/_pdf/tm/401-500/ tm474rev.pdf.]

McFarquhar, G. M., S. Iacobellis, and R. C. J. Somerville, 2003: SCM simulations of tropical ice clouds using observationally based parameterizations of microphysics. J. Climate, 16, $1643-$ 1664.

Mellor, G. L., and T. Yamada, 1982: Development of a turbulence closure model for geophysical fluid problems. Rev. Geophys. Space Phys., 20, 851-875.

Menzel, W. P., 1996: Report from the Working Group on Verification Statistics. Proc. Third Int. Winds Workshop, Ascona, Switzerland, Int. Satellite Winds Working Group, 3 pp. [Available online at http://cimss.ssec.wisc.edu/iwwg/iww3/ p17-19_WGReport3.pdf.]

Nieman, S. J., W. P. Menzel, C. M. Hayden, D. Gray, S. T. Wanzong, C. S. Velden, and J. Daniels, 1997: Fully automated cloud-drift winds in NESDIS operations. Bull. Amer. Meteor. Soc., 78, $1121-1133$
Otkin, J. A., T. J. Greenwald, J. Sieglaff, and H.-L. Huang, 2009: Validation of a large-scale simulated brightness temperature dataset using SEVIRI satellite observations. J. Appl. Meteor. Climatol., 48, 1613-1626.

Saunders, R., and Coauthors, 2008: What can RTTOV-9 do for me? Proc. 16th Int. TOVS Study Conf., Angra dos Reis, Int. ATOVS Working Group, 8 pp. [Available online at http:// cimss.ssec.wisc.edu/itwg/itsc/itsc16/proceedings/3_2_Saunders. pdf.]

Schmetz, J., K. Holmlund, J. Hoffman, B. Strauss, B. Mason, V. Gaertner, A. Koch, and L. V. D. Berg, 1993: Operational cloud-motion winds from Meteosat infrared images. J. Appl. Meteor., 32, 1206-1225.

Sherlock, V., 1999: ISEM-6: Infrared Surface Emissivity Model for RTTOV-6. Met Office Forecasting Research Tech. Rep. FR-299, 17 pp. [Available online at http://research.metoffice. gov.uk/research/interproj/nwpsaf/rtm/papers/isem6.pdf.]

Skamarock, W. C., J. B. Klemp, J. Dudhia, D. O. Gill, D. M. Barker, W. Wang, and J. G. Powers, 2005: A description of the Advanced Research WRF version 2. NCAR Tech. Note TN468+STR, 88 pp. [Available online at http://www.mmm.ucar. edu/wrf/users/docs/arw_v2.pdf.]

Thompson, G., P. R. Field, R. M. Rasmussen, and W. Hall, 2008: Explicit forecasts of winter precipitation using an improved bulk microphysics scheme. Part II: Implementation of a new snow parameterization. Mon. Wea. Rev., 136, 5095-5115.

Velden, C. S., and K. M. Bedka, 2009: Identifying the uncertainty in determining satellite-derived atmospheric motion vector height attribution. J. Appl. Meteor. Climatol., 48, 450-463.

_ C. M. Hayden, S. J. Nieman, W. P. Menzel, S. T. Wanzong, and J. S. Goerss, 1997: Upper-tropospheric winds derived from geostationary satellite water vapor observations. Bull. Amer. Meteor. Soc., 78, 173-195.

von Bremen, L., 2008: Using simulated satellite images to improve the characterization of atmospheric motion vectors (AMVs) and their errors for numerical weather prediction. NWP SAF Rep. NWPSAF-EC-VS-015, 41 pp. [Available online at http:// research.metoffice.gov.uk/research/interproj/nwpsaf/vs reports/nwpsaf-ec-vs-015.pdf.]

Wanzong, S., I. Genkova, C. S. Velden, and D. A. Santek, 2008: AMV research using simulated datasets. Proc. Ninth Int. Winds Workshop, Annapolis, MD, Int. Satellite Winds Working Group, 8 pp. [Available online at http://www.eumetsat.int/groups/cps/ documents/document/pdf_conf_p51_s5_25_wanzong_v.pdf.] 